\title{
Public Awareness And Knowledge Of Factors Associated With Myopia In Kisumu County, Western Kenya
}

Shadrack Muma ( $\square$ mumashadrack275@gmail.com )

Maseno University https://orcid.org/0000-0002-0598-1632

Stephen Obonyo

Strathmore University

Research article

Keywords:

Posted Date: March 23rd, 2020

DOI: https://doi.org/10.21203/rs.3.rs-17950/v1

License: (c) (1) This work is licensed under a Creative Commons Attribution 4.0 International License.

Read Full License 


\section{Abstract}

Background: Myopia is a global public health priority. Many modifiable and non modifiable risk factors have been shown to influence the development of myopia, but these factors are not adequately known by the general public. This study assessed public awareness of the factors that are associated with myopia among the general population in Kisumu County, Kenya.

Methods: A cross-sectional study was conducted from October 2019 to February 2020 using an Internetbased questionnaire. We collected basic socio demographic characteristics and investigated participants' knowledge of risk and protective factors that are associated with myopia. The primary outcome measures were the proportions of participants who identified each option as a risk factor. Logistic regression analysis was performed to compare levels of the knowledge of factors that are associated with myopia across populations with different demographic characteristics.

Results: Data from a total of 3,000 respondents were analyzed. The percentages of participants who accurately identified myopia risk factors were the following: $84.24 \%$ for genetics, $65.07 \%$ for reading and close up work, $56.68 \%$ for environmental conditions, $48.74 \%$ for visual stress, and $42.66 \%$ for diabetes. The percentages of participants who accurately identified myopia corrections were as follows: $90.00 \%$ for corrective lenses, $84.69 \%$ for corneal refractive surgery and $80.92 \%$ for refractive surgery. The majority of Kisumu residents correctly recognized the role of lifestyle factors in the development of myopia but not genetic factors. Levels of knowledge of the factors that are associated with myopia were significantly distinct across populations with different characteristics. The following socio demographic characteristics were associated with more comprehensive knowledge of myopia risk and corrective measures: women, young age, high education levels, white-collar jobs, and history of myopia in a family.

Conclusions: Public awareness and knowledge of risk and corrective measures for myopia in Kisumu is still insufficient. More efforts are needed to publicize information about myopia to reduce risk and prevent myopia

\section{Background}

Myopia is an enormous global health problem. In 2012, myopia was estimated to affect 108 million people globally (Kandel et al., 2018; Stone \& Shea, 2019). According to the 2010 Global Burden of Disease Study, approximately 1893 million people suffered from myopia worldwide in 2016 (Grzybowski, Kanclerz, \& Muzyka-wo, 2019) Moreover, this number is estimated to increase to 4949 million by 2050, and the majority of these individuals will likely come from low- and middle-income countries (Ferraz, Corrente, Opromolla, \& Schellini, 2014; Phec, 2017). Unfortunately, to date, no treatments are available to cure myopia or alter its progressive course unless a proper correction is given at the right time. Preventing myopia has become crucial. Evidence shows that immutable factors such as genetics, lifestyle, and environmental variables play important roles in the progression of myopia (Kandel, Khadka, Goggin, \& Pesudovs, 2017b; Plan, 2018). Thus, identifying and avoiding exposure to these modifiable risk factors 
may facilitate the prevention of myopia (Kandel, Khadka, Goggin, \& Pesudovs, 2017a) and help reduce disease burden that is associated with myopia (Holden et al., 2008, 2016).

Numerous studies have explored the factors that influence the development of myopia. Accumulating evidence suggests that reducing the rate of myopia progression by $50 \%$ could reduce the prevalence of high myopia by up to $90 \%$ (Resnikoff, Pascolini, Mariotti, \& Pokharel, 2008a). People who are myopic are at greater risk of developing glaucoma and cataract, however they may be protective against age related macular degeneration and diabetic retinopathy (Schneider et al., 2020) environmental influences, genetics and parental history have a higher risk of developing myopia (Kotingo, U, Tochi, Ejime, \& Taribo, 2014). However, although various risk and corrective measures for myopia have been identified, they have not been adequately popularized and recognized among the general public. For example, a systematic review assessed knowledge and attitudes about myopia prevention and treatment and found that public knowledge about the modifiable nature of myopia prevention remained inadequate, although this situation might improve over time (Nowak, 2018).

A recent survey from Taiwan showed that the majority of community-dwelling people were unaware of the relationship between time spent outdoors and behavioral influences with myopia (Hsieh \& Lin, 2016). Most investigations of knowledge and attitudes about myopia prevention have been conducted in highincome countries. Levels of knowledge of the potential for myopia prevention among individuals who live in other countries, such as Kenya, are largely unknown(Rodriguez \& Romero, 2014). Life expectancies have risen sharply over recent decades, and myopia is a serious health problem in Kenya. The agestandardized prevalence of myopia in Kenya increased by $8.6 \%$ from 1990 to 2016, while the worldwide prevalence increased by only $2.7 \%$ (Das \& Gupta, 2017). The estimated number of cases of myopia and total annual costs that are associated with myopia in Kenya is predicted to reach 24.25 million people and USD\$114.2 million in 2050 (Aldebasi, 2014). The worldwide costs that are associated with myopia accounted for $1.09 \%$ of the global gross domestic product, whereas such costs accounts for $1.47 \%$ in Kenya, indicating that the burden of myopia is even higher in Kenya compared with the world average (Mcdonnell, Lee, Spritzer, Lindblad, \& Hays, 2003). Thus, effective measures are needed to facilitate myopia prevention and reduce disease burden that is caused by myopia in Kenya (Resnikoff, Pascolini, Mariotti, \& Pokharel, 2008b).

However, insufficient awareness and knowledge of the potential of myopia prevention among the Kenyans public has been a substantial obstacle (Latorre-arteaga et al., 2014). Some studies evaluated the Kenyan population's overall understanding of Myopia, suggesting that the recognition of myopia needs to be improved (Thurston \& Ireland, 2011). The awareness of specific protective and risk factors that are associated with myopia among the Kenyan population is deficient. To identify specific target populations and develop strategies for myopia prevention, a better understanding of these factors is needed in populations with different socio demographic backgrounds.

\section{Methods}




\section{Study design}

An online questionnaire that evaluated general knowledge of myopia was disseminated via Whatsapp a social media outlet that is widely used in Kenya from October 2019 to February 2020. We invited Kisumu residents to complete the questionnaire. The study was approved by the Institutional Review Board of Maseno University. The surveys that were used in this study could be answered anonymously, and participation was voluntary. Thus, consent was assumed by the voluntary choice to participate. We collected a total of 3,000 questionnaires. Incomplete questionnaires were excluded. A total of 3,000 questionnaires were available for analysis.

\section{Questionnaire}

The questionnaire was written in Kiswahili and English and included two parts: (1) basic socio demographic information, including gender, age, education level, type of job, income, type of residence, and whether the respondent had contact with anyone who lived with myopia, and (2) the following multiple-choice questions: "Which factors do you think can increase the risk of myopia?" "Which factors do you do think can reduce the risk of myopia?" The questionnaire took approximately 5 minutes to complete.

\section{Statistical analysis}

Frequency distributions of all socio demographic characteristics and the proportion of Participants who identified each item as a risk or protective factor were calculated. We conducted multiple logistic regression analysis to compare the knowledge of factors for each item, stratified by demographic variables. We calculated odds ratios (ORs) and 95\% confidence intervals (Cls). SPSS 17 software was used to analyze the data. Values of $p<0.05$ were considered statistically significant.

\section{Results}

\section{Characteristics of the subjects}

In the present study, data from 3,000 eligible samples were analyzed. Table 1 shows the demographic characteristics of the respondents (1,200 males and 1,800 females). The average age was $39.23 \pm$ 12.50 years. The proportions of different education levels, including primary school or illiteracy, middle school, college or university, and postgraduate education, were $1.71 \%, 18.51 \%, 50.00 \%$, and $29.78 \%$, respectively. A majority of the subjects were white-collar workers (77.29\%) with income of 2000-10000 Kenya shillings per month $(66.12 \%)$ and lived in the city $(86.70 \%)$. Nearly one-third of the participants reported that they previously had contact with someone with myopia. 
Table 1

Characteristics of the participants.

\begin{tabular}{|lll|}
\hline & Number & Weighted proportion \\
\hline Gender & & \\
\hline Men & 1200 & $34.57 \%$ \\
\hline Women & 1800 & $65.43 \%$ \\
\hline Age (years) & & \\
\hline$<40$ & 1800 & $55.27 \%$ \\
\hline $40-65$ & 1000 & $41.55 \%$ \\
\hline$\geq 65$ & 200 & $3.18 \%$ \\
\hline Education level & & \\
\hline Primary school or illiteracy & 200 & $1.71 \%$ \\
\hline Middle or high school & 500 & $18.51 \%$ \\
\hline College or university & 1500 & $50.00 \%$ \\
\hline Postgraduate & 800 & $29.78 \%$ \\
\hline Type of job & & \\
\hline White-collar & 1100 & $29.30 \%$ \\
\hline Blue-collar & 1200 & $36.82 \%$ \\
\hline Retired & 650 & $22.92 \%$ \\
\hline Income group (KSH/month) & & $8.69 \%$ \\
\hline $0-2000$ & 50 & 1000 \\
\hline $2000-5000$ & 1000 & $12.13 \%$ \\
\hline $5000-10000$ & 400 & $10.58 \%$ \\
\hline$>10000$ & & \\
\hline Type of residence & & \\
\hline City & & \\
\hline Town & & \\
\hline Rural area & & \\
\hline Myopia contact & & \\
\hline
\end{tabular}




\begin{tabular}{|l|lll|}
\hline & Number & Weighted proportion \\
\cline { 2 - 3 } & Yes & 1100 & $32.98 \%$ \\
\hline No & 1600 & $50.21 \%$ \\
\cline { 2 - 3 } & Unclear & 300 & $16.81 \%$ \\
\cline { 2 - 3 } & Awareness and understanding of myopia risk factors
\end{tabular}

The proportions of each item that was identified by the respondents as a risk factor for myopia. Most of the participants were able to correctly recognize at least one risk factor, but $5.51 \%$ of them were unable to correctly recognize any risk factor. The percentages of the participants who accurately identified the following risk factors for dementia were $84.24 \%$ for genetics, $65.07 \%$ for reading and close up work, $56.68 \%$ for environmental conditions, $48.74 \%$ for visual stress, and $42.66 \%$ for diabetes.

We next assessed the relationship between socio demographic characteristics and knowledge of myopia risk factors using multiple logistic regression analysis (Table 2). Compared with men, more women believed genetics $(\mathrm{OR}=1.68,95 \% \mathrm{Cl}=1.37-2.05)$ was a risk factor for myopia. The age-specific analysis found that middle-aged individuals (40-65 years old) were significantly less likely to identify the contribution of genetics $(\mathrm{OR}=0.69,95 \% \mathrm{Cl}=0.56-0.86)$, reading and close up work $(\mathrm{OR}=0.83,95 \% \mathrm{Cl}=$ $0.71-0.99)$, and environmental conditions $(\mathrm{OR}=0.67,95 \% \mathrm{Cl}=0.57-0.79)$ to the progression of myopia compared with younger individuals ( $<40$ years old), indicating that the older age group might have lower levels of knowledge of myopia risk factors. Additionally, the group with a higher level of education (college, university, and postgraduate education) had a better understanding of all five myopia risk factors. 
Table 2

Demographic and social factors associated with knowledge of risk factors for myopia.

\begin{tabular}{|c|c|c|c|c|c|c|c|c|c|}
\hline & \multicolumn{3}{|c|}{ Genetic } & \multicolumn{3}{|c|}{ Environmental factors } & \multicolumn{3}{|c|}{ Diabetes } \\
\hline & $\%$ & OR & $\begin{array}{l}95 \% \\
\mathrm{Cl}\end{array}$ & $\%$ & OR & $\begin{array}{l}95 \% \\
\mathrm{Cl}\end{array}$ & $\%$ & OR & $\begin{array}{l}95 \% \\
\mathrm{C}\end{array}$ \\
\hline \multicolumn{10}{|l|}{ Gender } \\
\hline Men & 80.80 & 1 & & 64.60 & 1 & & 55.10 & 1 & \\
\hline Women & 86.10 & $1.68^{*}$ & $\begin{array}{l}1.37- \\
2.05\end{array}$ & 65.30 & 1.10 & $\begin{array}{l}0.94- \\
1.29\end{array}$ & 57.50 & 1.14 & $\begin{array}{l}0.98- \\
1.33\end{array}$ \\
\hline \multicolumn{10}{|l|}{ Age (years) } \\
\hline$<40$ & 87.70 & 1 & & 69.40 & 1 & & 63.30 & 1 & \\
\hline $40-65$ & 80.00 & $0.69 *$ & $\begin{array}{l}0.56- \\
0.86\end{array}$ & 60.60 & $0.83^{*}$ & $\begin{array}{l}0.71- \\
0.99\end{array}$ & 49.20 & $0.67 *$ & $\begin{array}{l}0.57- \\
0.79\end{array}$ \\
\hline$\geq 65$ & 79.20 & 1.19 & $\begin{array}{l}0.67- \\
2.11\end{array}$ & 48.10 & 0.79 & $\begin{array}{l}0.50- \\
1.25\end{array}$ & 38.70 & 0.64 & $\begin{array}{l}0.40- \\
1.02\end{array}$ \\
\hline \multicolumn{10}{|l|}{ Education level } \\
\hline $\begin{array}{l}\text { Primary school or } \\
\text { illiteracy }\end{array}$ & 59.60 & 1 & & 38.60 & 1 & & 31.60 & 1 & \\
\hline Middle or high school & 73.50 & $2.02^{*}$ & $\begin{array}{l}1.13- \\
3.60\end{array}$ & 49.70 & 1.58 & $\begin{array}{l}0.89- \\
2.78\end{array}$ & 40.30 & 1.41 & $\begin{array}{l}0.78- \\
2.54\end{array}$ \\
\hline College or university & 86.80 & $3.78^{*}$ & $\begin{array}{l}2.07- \\
6.89\end{array}$ & 67.20 & $2.61 *$ & $\begin{array}{l}1.47- \\
4.66\end{array}$ & 59.30 & $2.25^{\star}$ & $\begin{array}{l}1.24- \\
4.10\end{array}$ \\
\hline Postgraduate & 88.10 & $3.69 *$ & $\begin{array}{l}1.95- \\
6.97\end{array}$ & 72.60 & $3.13^{\star}$ & $\begin{array}{l}1.72- \\
5.70\end{array}$ & 63.90 & $2.47^{\star}$ & $\begin{array}{l}1.33- \\
4.57\end{array}$ \\
\hline \multicolumn{10}{|l|}{ Type of job } \\
\hline White-collar & 86.70 & 1 & & 69.20 & 1 & & 61.00 & 1 & \\
\hline Blue-collar & 78.50 & 0.95 & $\begin{array}{l}0.69- \\
1.31\end{array}$ & 54.60 & 0.78 & $\begin{array}{l}0.61- \\
1.00\end{array}$ & 45.20 & $0.75^{\star}$ & $\begin{array}{l}0.59 \\
0.96\end{array}$ \\
\hline Retired & 72.80 & $0.55^{\star}$ & $\begin{array}{l}0.39- \\
0.76\end{array}$ & 46.70 & $0.56^{*}$ & $\begin{array}{l}0.43- \\
0.74\end{array}$ & 38.20 & $0.60 *$ & $\begin{array}{l}0.45 \\
0.79\end{array}$ \\
\hline \multicolumn{10}{|l|}{$\begin{array}{l}\text { Income groups } \\
\text { (KSH/month) }\end{array}$} \\
\hline $0-2000$ & 80.60 & 1 & & 59.60 & 1 & & 54.60 & 1 & \\
\hline $2000-5000$ & 82.40 & 1.09 & $\begin{array}{l}0.79- \\
1.51\end{array}$ & 60.80 & 1.08 & $\begin{array}{l}0.83- \\
1.40\end{array}$ & 53.00 & 0.95 & $\begin{array}{l}0.73- \\
1.23\end{array}$ \\
\hline
\end{tabular}




\begin{tabular}{|c|c|c|c|c|c|c|c|c|c|}
\hline \multirow[b]{2}{*}{$5000-10000$} & \multicolumn{3}{|c|}{ Genetic } & \multicolumn{3}{|c|}{ Environmental factors } & \multicolumn{3}{|c|}{ Diabetes } \\
\hline & 84.40 & 0.96 & $\begin{array}{l}0.69- \\
1.34\end{array}$ & 67.20 & 1.13 & $\begin{array}{l}0.87- \\
1.47\end{array}$ & 58.90 & 0.95 & $\begin{array}{l}0.74- \\
1.23\end{array}$ \\
\hline$>10000$ & 88.10 & 1.35 & $\begin{array}{l}0.92- \\
1.97\end{array}$ & 69.70 & 1.13 & $\begin{array}{l}0.85- \\
1.51\end{array}$ & 58.80 & 0.88 & $\begin{array}{l}0.66- \\
1.16\end{array}$ \\
\hline \multicolumn{10}{|c|}{ Type of residence } \\
\hline City & 87.70 & 1 & & 65.80 & 1 & & 58.10 & 1 & \\
\hline Town & 79.70 & 0.90 & $\begin{array}{l}0.65- \\
1.25\end{array}$ & 62.10 & 1.13 & $\begin{array}{l}0.86- \\
1.47\end{array}$ & 48.30 & 0.84 & $\begin{array}{l}0.65- \\
1.09\end{array}$ \\
\hline Rural area & 75.30 & 0.79 & $\begin{array}{l}0.52- \\
1.21\end{array}$ & 57.10 & 1.09 & $\begin{array}{l}0.76- \\
1.56\end{array}$ & 46.10 & 0.86 & $\begin{array}{l}0.60- \\
1.23\end{array}$ \\
\hline \multicolumn{10}{|c|}{ Myopia contact } \\
\hline Yes & 85.90 & 1 & & 69.10 & 1 & & 59.20 & 1 & \\
\hline No & 82.80 & $0.73^{*}$ & $\begin{array}{l}0.59- \\
0.91\end{array}$ & 62.90 & $0.72^{\star}$ & $\begin{array}{l}0.61- \\
0.86\end{array}$ & 55.00 & $0.77 *$ & $\begin{array}{l}0.66- \\
0.91\end{array}$ \\
\hline Unclear & 85.20 & 1.00 & $\begin{array}{l}0.74- \\
1.35\end{array}$ & 63.60 & 0.82 & $\begin{array}{l}0.65- \\
1.02\end{array}$ & 56.70 & 0.91 & $\begin{array}{l}0.73- \\
1.12\end{array}$ \\
\hline
\end{tabular}

In addition to gender, age, and education level, the type of job and contact with people with myopia also influenced the awareness of myopia risk factors. Blue-collar workers had a poorer understanding of the relationship between diabetes and dementia $(\mathrm{OR}=0.75,95 \% \mathrm{Cl}=0.59-0.96)$ compared with white-collar workers, and retired people had an insufficient understanding of all myopia risk factors. Respondents who were never in contact with individuals with myopia were less likely to realize the roles that genetic $(\mathrm{OR}=0.73,95 \% \mathrm{Cl}=0.59-0.91)$, diabetes $(\mathrm{OR}=0.72,95 \% \mathrm{Cl}=0.61-0.86)$, environmental factors $(\mathrm{OR}=$ $0.77,95 \% \mathrm{Cl}=0.66-0.91)$, and reading and close up work $(\mathrm{OR}=0.63,95 \% \mathrm{Cl}=0.54-0.74)$ play in the development and progression of myopia. The awareness of risk factors for myopia was not influenced by income or type of residence.

\section{Awareness and understanding of myopia protective factors}

The proportion of participants who chose none of the five items as protective factors were $4.79 \%$. Most of the respondents correctly recognized $90.00 \%$ for corrective lenses, $84.69 \%$ for corneal refractive surgery and $80.92 \%$ for refractive surgery as protective factors for myopia. However, only $6.14 \%$ of the individuals were aware that wearing full correction was beneficial for delaying the onset of myopia progression. Multiple logistic regression analysis was used to explore the effects of socio demographic characteristics on the understanding of protective factors of myopia (Table 3). Gender, age, education level, type of job, and contact with individuals with myopia had distinct influences on the awareness of protective factors for myopia. Income and type of residence did not influence the awareness of protective factors for myopia. 
Table 3

Demographic and social factors associated with knowledge of protective factors for myopia.

\begin{tabular}{|c|c|c|c|c|c|c|c|c|c|}
\hline & \multicolumn{3}{|c|}{ Optical correction } & \multicolumn{3}{|c|}{$\begin{array}{l}\text { Corneal refractive } \\
\text { surgery }\end{array}$} & \multicolumn{3}{|c|}{ Refractive surgery } \\
\hline & $\%$ & OR & $\begin{array}{l}95 \% \\
\mathrm{Cl}\end{array}$ & $\%$ & OR & $\begin{array}{l}95 \% \\
\mathrm{Cl}\end{array}$ & $\%$ & OR & $\begin{array}{l}95 \% \\
\mathrm{Cl}\end{array}$ \\
\hline \multicolumn{10}{|l|}{ Gender } \\
\hline Men & 89.17 & 1 & & 79.55 & 1 & & 74.61 & 1 & \\
\hline Women & 90.43 & $1.33^{*}$ & $\begin{array}{l}1.04- \\
1.72\end{array}$ & 87.41 & $1.92^{\star}$ & $\begin{array}{l}1.57- \\
2.35\end{array}$ & 84.25 & $2.21^{\star}$ & $\begin{array}{l}1.82- \\
2.69\end{array}$ \\
\hline \multicolumn{10}{|l|}{ Age (years) } \\
\hline$<40$ & 93.60 & 1 & & 87.37 & 1 & & 88.40 & 1 & \\
\hline $40-65$ & 86.52 & $0.60 *$ & $\begin{array}{l}0.45- \\
0.79\end{array}$ & 82.26 & 0.82 & $\begin{array}{l}0.65- \\
1.02\end{array}$ & 72.60 & $0.47^{\star}$ & $\begin{array}{l}0.38- \\
0.58\end{array}$ \\
\hline$\geq 65$ & 72.64 & $0.41 *$ & $\begin{array}{l}0.23- \\
0.72\end{array}$ & 69.81 & 0.54 & $\begin{array}{l}0.32- \\
0.92\end{array}$ & 59.43 & $0.43^{*}$ & $\begin{array}{l}0.26- \\
0.72\end{array}$ \\
\hline \multicolumn{10}{|l|}{ Education level } \\
\hline $\begin{array}{l}\text { Primary school or } \\
\text { illiteracy }\end{array}$ & 64.91 & 1 & & 56.14 & 1 & & 35.09 & 1 & \\
\hline $\begin{array}{l}\text { Middle or high } \\
\text { school }\end{array}$ & 80.42 & $2.26^{*}$ & $\begin{array}{l}1.23- \\
4.13\end{array}$ & 73.30 & $2.12^{\star}$ & $\begin{array}{l}1.19- \\
3.76\end{array}$ & 60.52 & $3.19 *$ & $\begin{array}{l}1.76- \\
5.80\end{array}$ \\
\hline $\begin{array}{l}\text { College or } \\
\text { university }\end{array}$ & 91.19 & $3.62^{*}$ & $\begin{array}{l}1.91- \\
6.85\end{array}$ & 85.68 & $3.70 *$ & $\begin{array}{l}2.04- \\
6.72\end{array}$ & 84.66 & $7.75^{\star}$ & $\begin{array}{l}4.18- \\
14.36\end{array}$ \\
\hline Postgraduate & 95.37 & $5.47 *$ & $\begin{array}{l}2.68- \\
11.15\end{array}$ & 91.75 & $6.37 \star$ & $\begin{array}{l}3.35- \\
12.12\end{array}$ & 89.94 & $11.21^{*}$ & $\begin{array}{l}5.82- \\
21.59\end{array}$ \\
\hline \multicolumn{10}{|l|}{ Type of job } \\
\hline White-collar & 93.02 & 1 & & 87.36 & 1 & & 85.54 & 1 & \\
\hline Blue-collar & 82.47 & $0.64^{*}$ & $\begin{array}{l}0.45- \\
0.92\end{array}$ & 74.07 & 0.75 & $\begin{array}{l}0.56- \\
1.02\end{array}$ & 68.89 & 0.85 & $\begin{array}{l}0.63- \\
1.14\end{array}$ \\
\hline Retired & 76.49 & $0.53 *$ & $\begin{array}{l}0.36- \\
0.77\end{array}$ & 77.34 & 0.86 & $\begin{array}{l}0.60- \\
1.23\end{array}$ & 60.91 & $0.57 *$ & $\begin{array}{l}0.42- \\
0.79\end{array}$ \\
\hline \multicolumn{10}{|l|}{$\begin{array}{l}\text { Income groups } \\
\text { (KSH/month) }\end{array}$} \\
\hline $0-2000$ & 86.61 & 1 & & 80.33 & 1 & & 75.68 & 1 & \\
\hline $2000-5000$ & 86.50 & 1.02 & $\begin{array}{l}0.70- \\
1.48\end{array}$ & 82.31 & 1.21 & $\begin{array}{l}0.87- \\
1.66\end{array}$ & 75.56 & 1.01 & $\begin{array}{l}0.73- \\
1.38\end{array}$ \\
\hline
\end{tabular}




\begin{tabular}{|c|c|c|c|c|c|c|c|c|c|}
\hline \multirow[b]{2}{*}{$5000-10000$} & \multicolumn{3}{|c|}{ Optical correction } & \multicolumn{3}{|c|}{$\begin{array}{l}\text { Corneal refractive } \\
\text { surgery }\end{array}$} & \multicolumn{3}{|c|}{ Refractive surgery } \\
\hline & 90.97 & 1.15 & $\begin{array}{l}0.77- \\
1.72\end{array}$ & 85.68 & 1.18 & $\begin{array}{l}0.85- \\
1.65\end{array}$ & 84.95 & 1.29 & $\begin{array}{l}0.93- \\
1.80\end{array}$ \\
\hline$>10000$ & 94.51 & 1.61 & $\begin{array}{l}0.99- \\
2.63\end{array}$ & 88.24 & 1.31 & $\begin{array}{l}0.90- \\
1.92\end{array}$ & 83.79 & 1.04 & $\begin{array}{l}0.72- \\
1.51\end{array}$ \\
\hline \multicolumn{10}{|c|}{ Type of residence } \\
\hline City & 90.50 & 1 & & 85.83 & 1 & & 82.38 & 1 & \\
\hline Town & 88.62 & 1.32 & $\begin{array}{l}0.87- \\
1.98\end{array}$ & 77.93 & 0.89 & $\begin{array}{l}0.64- \\
1.22\end{array}$ & 74.83 & 1.07 & $\begin{array}{l}0.78- \\
1.46\end{array}$ \\
\hline Rural area & 83.12 & 1.01 & $\begin{array}{l}0.61- \\
1.66\end{array}$ & 75.97 & 1.04 & $\begin{array}{l}0.68- \\
1.61\end{array}$ & 64.94 & 0.78 & $\begin{array}{l}0.52- \\
1.18\end{array}$ \\
\hline \multicolumn{10}{|c|}{ Dementia contact } \\
\hline Yes & 91.19 & 1 & & 87.19 & 1 & & 82.02 & 1 & \\
\hline No & 90.21 & 0.84 & $\begin{array}{l}0.64- \\
1.11\end{array}$ & 84.19 & $0.78^{*}$ & $\begin{array}{l}0.62- \\
0.98\end{array}$ & 81.68 & 0.89 & $\begin{array}{l}0.72- \\
1.10\end{array}$ \\
\hline Unclear & 86.99 & $0.71^{\star}$ & $\begin{array}{l}0.50- \\
0.99\end{array}$ & 81.28 & $0.70 *$ & $\begin{array}{l}0.53- \\
0.94\end{array}$ & 76.47 & $0.74^{*}$ & $\begin{array}{l}0.56- \\
0.97\end{array}$ \\
\hline
\end{tabular}

Compared with men, women knew more about the roles of optical correction $(\mathrm{OR}=1.33,95 \% \mathrm{Cl}=1.04-$ 1.72), refractive error surgery $(O R=1.92,95 \% \mathrm{Cl}=1.57-2.35)$, and corneal refractive surgery $(O R=1.96$, $95 \% \mathrm{Cl}=1.65-2.33$ ) in preventing myopia. Compared with younger individuals ( $<40$ years old), middleaged subjects and elderly individuals were less aware that refractive surgery (40-65 years old: $O R=0.60$, $95 \% \mathrm{Cl}=0.45-0.79 ; \geq 65$ years old: $\mathrm{OR}=0.41,95 \% \mathrm{Cl}=0.23-0.72)$, corneal surgery $(40-65$ years old: $\mathrm{OR}$ $=0.47,95 \% \mathrm{Cl}=0.38-0.58 ; \geq 65$ years old: $\mathrm{OR}=0.43,95 \% \mathrm{Cl}=0.26-0.72$ ), and optical correction (4065 years old: $\mathrm{OR}=0.79,95 \% \mathrm{Cl}=0.65-0.95 ; \geq 65$ years old, $\mathrm{OR}=0.51,95 \% \mathrm{Cl}=0.31-0.83$ ) were protective factors. People with a higher level of education had a better understanding of lifestyle variables that were protective factors for myopia, with the exception of ocular drugs. Compared with white-collar workers, blue-collar workers had lower knowledge that optical correction $(\mathrm{OR}=0.64,95 \% \mathrm{Cl}=$ $0.45-0.92)$ and refractive surgery $(\mathrm{OR}=0.70,95 \% \mathrm{Cl}=0.53-0.91)$ were protective factors. Individuals who had contact with those having myopia had a better understanding that optical correction and corneal surgery were protective factors for myopia.

\section{Discussions}

The present study investigated public knowledge and awareness of the factors that are associated with myopia in Kisumu using a relatively large sample. We found that the residents had an extensive but not a comprehensive understanding of myopia. Most people could correctly recognize evidence-based risk and 
protective factors. However, a majority of the respondents were unaware of the role of environmental factors in the development of myopia. Additionally, the understanding of factors that are related to myopia was significantly associated with socio demographic variables, such as gender, age, education level, type of job, and contact with individuals with myopia. These findings underscore the necessity to expend more effort to promote the public knowledge of myopia in Kisumu and develop different strategies for people with different backgrounds.

Previous studies suggested that knowledge of the possibility that myopia can be prevented remains poor in general. A few studies that were conducted in Kenya mainly focused on the recognition of eye strain symptom of myopia (Dawson \& Schwab, 2012; Reutens, 2016). The present results suggest that the overall understanding of factors that are associated with myopia among Kisumu population is more comprehensive than we initially believed based on similar studies in other countries (Resnikoff et al., 2008b). This finding may have two explanations. First, the respondents in the present study had a relatively high level of education and may be able to absorb more accurate information about myopia. Secondly, we used an online questionnaire and invited people to participate through the Internet, suggesting that our respondents may have better access to information about eye health compared with the general public. Future studies should compare the public's awareness of myopia between Kenya and other countries and evaluate the role of the Internet in disseminating eye health information.

The factors that are associated with myopia and were used as response options in the present study can be divided into two categories: environmental and genetic factors (Plackal, Ismail, \& Mohanraj, 2018).

Most of the respondents correctly recognized the relationship between corrective measures and myopia, but they often misunderstood the contribution of environmental factors and genetics to the development of myopia. This may be explained by the fact that the publicity of disease prevention mainly focuses on optical correction (Sheetal, 2011) thus neglecting the fact that chronic diseases, including diabetes, are risk factors for myopia (Hashemi, Fotouhi, Yekta, Pakzad, \& Ostadimoghaddam, 2018). Moreover, spectacle wearing refusal is common in the general population (Grzybowski et al., 2019) and people often believe that spectacle correction destroys the eyes more (Dandona \& Dandona, 2006). Other studies also found that people had less knowledge about the role of environmental factors in the development of myopia (Sokoto et al., 2018). Thus, risk factors that are associated with the prevention of myopia need to be popularized in the general public.

Several socio demographic characteristics were independently associated with the knowledge of myopia risk and prevention factors. Several characteristics, including women, age $<40$ years, a high level of education, white-collar job, and having contact with individuals with myopia, were associated with a more extensive understanding of myopia, which is partially consistent with previous surveys that were conducted in Nakuru (Naidoo \& Jaggernath, 2010). Women often have a better understanding of myopia in both Kenya and other countries (District, Sewunet, Aredo, \& Gedefew, 2014). Individuals with a high level of education or previous contact with myopia patients had significantly better knowledge of risk and protective factors for myopia (West, 2012) which may be attributable to a higher probability of accessing 
information about myopia. In the present study and another survey that was conducted in Asia (Stone \& Shea, 2019) younger people had more knowledge about myopia than middle-aged and elderly individuals. These findings suggest the need to develop different approaches for different populations to disseminate knowledge about myopia. Because the present study had a limited number of subjects who had an income $<2000$ shillings/month and who were from rural areas, no significant influence of income or type of residence was found. Future studies should include more subjects who have a lower income and who are from rural areas.

The strengths of the present study include (1) investigating the knowledge of risk and protective factors for myopia in a relatively large sample of the Kisumu population and (2) exploring demographic characteristics that are associated with the level of knowledge of myopia. Informing the public about modifiable risk and protective factors may help reduce the incidence of myopia.

The present study also has several limitations. First, selection bias might have been unavoidable because of the use of an Internet-based social media application. Second, we used simple idioms instead of professional terms so that the response options could be more easily understood by the general public, which may have caused some ambiguity. Third, the response options that were used were not comprehensive, and other factors that are associated with myopia were not assessed.

\section{Conclusions}

In summary, the present Internet-based survey demonstrated substantial deficits in the public knowledge of modifiable factors for myopia in Kisumu. People with different characteristics may have distinct awareness of myopia risk. These findings indicate the importance of disseminating information about myopia in Kisumu and educating the public about the role of modifiable risk and preventive factors. More information about myopia risk reduction should be delivered to the public, and different promotion strategies are needed to achieve prevention.

\section{Declarations}

Availability of data and materialsl

The dataset for Kisumu County residents generated and analyzed during the current study are available from the corresponding author upon reasonable request.

Consent for publication

Not applicable.

\section{Ethics Approval}

The study obtained ethical clearance from Maseno University Ethics and Review Committee. Eligible participants signed written consent. Names were not used to safeguard the privacy of the participants but only relevant demographic information as well as random number code was used. A separate document 
that links the study code to participants identifying information was only accessible to the researcher.

Fact sheets on myopia were provided to the participants.

Competing interests

SM declares that they have no competing interest related to this study.

Funding

This research was fully funded by the corresponding author.

Author's contributions

$\mathrm{SM}$ is a PhD candidate. He initiated the research concept, developed the proposal, did the data collection, analyzed the data and wrote the manuscript. SO improved the research concept assisted with proposal development and reviewed the proposal, thesis and the manuscript. All authors contributed equally to the research work.

Acknowledgement

We wish to thank all residents who participated in this study and the research assistants.

\section{References}

Aldebasi, Y. H. (2014). Prevalence of correctable visual impairment in primary school children in Qassim Province, Saudi Arabia. Journal of Optometry, 7(3), 168-176.

https://doi.org/10.1016/j.optom.2014.02.001

Dandona, L., \& Dandona, R. (2006). What is the global burden of visual impairment?, 10. https://doi.org/10.1186/1741-7015-4-6

Das, D., \& Gupta, S. (2017). A study on refractive errors in school children with complaints of headache in a rural tertiary care hospital, 3(2), 192-197. https://doi.org/10.18231/2395-1451.2017.0048

Dawson, C. R., \& Schwab, I. R. (2012). Epidemiology of cataract-a major cause of preventable blindness *. Pakistan Journal of Ophthalmology, 5(1), 493-501.

District, M., Sewunet, S. A., Aredo, K. K., \& Gedefew, M. (2014). Uncorrected refractive error and associated factors among primary school children in Debre, 1-6.

Ferraz, F. H., Corrente, J. E., Opromolla, P., \& Schellini, S. A. (2014). Influence of uncorrected refractive error and unmet refractive error on visual impairment in a Brazilian population, 1-10.

Grzybowski, A., Kanclerz, P., \& Muzyka-wo, M. (2019). Methods for evaluating quality of life and vision in patients undergoing lens refractive surgery.

Hashemi, H., Fotouhi, A., Yekta, A., Pakzad, R., \& Ostadimoghaddam, H. (2018). ScienceDirect Global and regional estimates of prevalence of refractive errors: Systematic review and meta-analysis. Journal of Current Ophthalmology, 30(1), 3-22. https://doi.org/10.1016/j.joco.2017.08.009 
Holden, B. A., Fricke, T. R., Ho, S. M., Wong, R., Schlenther, G., \& Cronje, S. (2008). Global Vision Impairment Due to Uncorrected Presbyopia, 126(12), 1731-1739.

Holden, B. A., Fricke, T. R., Wilson, D. A., Jong, M., Naidoo, K. S., Sankaridurg, P., ... Resnikoff, S. (2016). Global Prevalence of Myopia and High Myopia and Temporal Trends from 2000 through 2050. Ophthalmology, 123(5), 1036-1042. https://doi.org/10.1016/j.ophtha.2016.01.006

Hsieh, M., \& Lin, J. (2016). Association of refractive error with vision-related quality of life in junior high school students. Taiwan Journal of Ophthalmology, 6(1), 32-35.

https://doi.org/10.1016/j.tjo.2015.12.001

Kandel, H., Khadka, J., Goggin, M., \& Pesudovs, K. (2017a). Patient-reported Outcomes for Assessment of Quality of Life in Refractive Error: A Systematic Review, 94(12), 1102-1119. https://doi.org/10.1097/OPX.0000000000001143

Kandel, H., Khadka, J., Goggin, M., \& Pesudovs, K. (2017b). Questionnaires for Measuring Refractive. https://doi.org/10.3928/1081597X-20170310-01

Kandel, H., Khadka, J., Shrestha, M. K., Sharma, S., Kandel, S. N., Dhungana, P., ... Pesudovs, K. (2018). Uncorrected and corrected refractive error experiences of Nepalese adults: a qualitative study, 6586. https://doi.org/10.1080/09286586.2017.1376338

Kotingo, E. L., U, O. D., Tochi, I. F., Ejime, E., \& Taribo, A. (2014). Effects of Reduced Visual Acuity on Academic Performance among Secondary School Students in, 3(4).

Latorre-arteaga, S., Gil-gonzález, D., Enciso, O., Phelan, A., Kohler, J., Gil-gonzález, D., ... Enciso, O. (2014). Reducing visual deficits caused by refractive errors in school and preschool children: results of a pilot school program in the Andean region of Apurimac, Peru, 9716. https://doi.org/10.3402/gha.v7.22656

Mcdonnell, P. J., Lee, P., Spritzer, K., Lindblad, A. S., \& Hays, R. D. (2003). Associations of Presbyopia With Vision-Targeted Health-Related Quality of Life, 121, 1577-1581.

Naidoo, K. S., \& Jaggernath, J. (n.d.). Community Ophthalmology Uncorrected refractive errors. https://doi.org/10.4103/0301-4738.100543

Nowak, M. S. (2018). Characteristics of Refractive Errors in a Population of Adults in the Central Region of Poland, 10-14. https://doi.org/10.3390/ijerph15010090

Phec, H. K. (2017). Original Article Impact of refractive error on quality of life: a qualitative study, (March), 677-688. https://doi.org/10.1111/ceo.12954

Plackal, J., Ismail, G., \& Mohanraj, K. (2018). Perception of Refractive Error among Adolescents - A Pilot Study, 6(2), 1-9. https://doi.org/10.21522/TIJPH.2013.06.02.Art013 
Plan, S. (2018). IAPB AFRICA HUMAN RESOURCES FOR EYE HEALTH, 2014-2018.

Primary, T. H. E., \& Care, E. Y. E. (n.d.-a). Care of the Patient with.

Primary, T. H. E., \& Care, E. Y. E. (n.d.-b). Learning Related Vision Problems.

Resnikoff, S., Pascolini, D., Mariotti, P., \& Pokharel, G. P. (2008a). Global magnitude of visual impairment caused by uncorrected refractive errors in 2004, 41210(June 2007), 63-70.

https://doi.org/10.2471/BLT.07.041210

Resnikoff, S., Pascolini, D., Mariotti, P., \& Pokharel, G. P. (2008b). Global magnitude of visual impairment caused by uncorrected refractive errors in 2004, 41210(January), 63-70.

https://doi.org/10.2471/BLT.07.041210

Reutens, D. C. (2016). Care of the Adult Patient with. J. Evid. Based Med. Healthc, 1(5), 1-6.

Rodriguez, N. M., \& Romero, A. F. (2014). The prevalence of refractive conditions in Puerto Rican adults attending an eye clinic system. Journal of Optometry, 7(3), 161-167.

https://doi.org/10.1016/j.optom.2013.06.001

Schneider, J., Hons, B., Leeder, S. R., Gopinath, B., Hons, B., Wang, J. J., \& Mitchell, P. (2020). MAJOR REVIEW Frequency, Course, and Impact of Correctable Visual Impairment ( Uncorrected Refractive Error ). Survey of Ophthalmology, 55(6), 539-560. https://doi.org/10.1016/j.survophthal.2010.02.004

Sheetal. (2011). The Perceptions Regarding Refractive Errors and Their Psychosocial Impact on Youth in Dakshina Kannada, 5(4), 746-748.

Sokoto, I. N., Olatunji, K., Oche, O. M., Adamu, H., Muhammad, A., Abdulsalam, L. B., \& Tahir, Y. (2018). RESEARCH ARTICLE VISUAL IMPAIRMENT AND ITS RELATIONSHIP TO ACADEMIC PERFORMANCE AMONG PRIMARY, 5(4), 3770-3774.

Stone, C., \& Shea, S. O. (2019). Older, online and first: Recommendations for retention and success, 35(1), 57-69.

Thurston, A., \& Ireland, N. (2011). Literature Review of Refractive Error and Its Article 4 A Potential Effect on Reading Attainment in the Early Years of School.

West, K. (2012). NIH Public Access, 118(5), 805-811.

https://doi.org/10.1016/j.ophtha.2010.09.015.Uncorrected 